UC-33

Reporting Date: January 1975 Issued: February 1975

\title{
Safety Test No. S-6, Launch Pad Abort Sequential Test Phase III: FSA Impacts
}

by

E. C. Snow

C. E. Frantz 
In the interest of prompi distribution, this LAMS report was not edited by the Technical Information staff.

Work supported by the ERDA Division of Space Nuclear Systems.

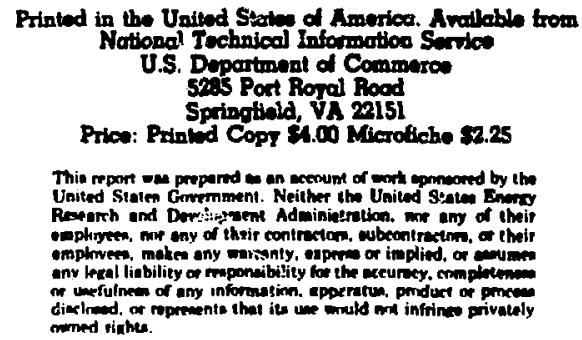




1.0.
2.0.
INTRODUCTION $\ldots \ldots \ldots \ldots \ldots \ldots$

3. 3. Double-Sphere Impact (Low Temperature). . . . 5

3. 3. 1. Test Operation. ............ 5

3.3.2. Results .............. 5

3.4. Reentry Impact on Concrete ......... 6

3.4.1. Test Operation ............ 6

3.4.2. Results ............. 6

3.5. Reentry Impact on Soil $\ldots \ldots \ldots \ldots \ldots$

3.5.1. Test Operation $\ldots \ldots \ldots \ldots \ldots .7$

3. 5.2. Results ............. 7

4.0. DISCUSSION $\ldots \ldots \ldots \ldots \ldots \ldots$

5. $0 . \quad$ CONCLUSIONS $\ldots \ldots \ldots \ldots \ldots \ldots$

This report was prepared as an account of work
sponsored by the United States Government. Neither
the United States nor the United States Energy
Research and Development Administration, nor any of
their employees, nor any of their contractors,
subcontractors, or thei employes, makes any
warranty, express or implied, or assumes any legal
liability or responsibility for the accuracy, completeness
of usefulness of any information, apparatus, product of
process disclosed, or represents that its use would not
infringe privately owned rights.

1

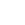

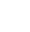

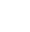

3




\title{
SAFETY TEST NO. S-6,LAUNCH PAD ABORT \\ SEQUENTIAL TEST PHASE III: FSA IMPACTS
}

by

E. C. Snow and C. E. Frantz

\begin{abstract}
Five FSA impact tests h2ve been conducted in the iASL gas gun facility as part of the MHW/LES 8-9 Launch Abort Test. Three of these were done at low or launch pad fall-back velocities of approximately $30 \mathrm{~m} / \mathrm{s}$ (100 fps), one was a single sphere impact on sharp steel and the other two were double sphere impacts on flat concrete at different temperatures. Two tests were also conducted at reentry velocities and temperatures, using targets of flat concrete and compact soil.

The PICS deformation resulting from these five impacts ranged from nearly zero in the case of the compact soil target to a hoop strain deformation of $7 \%$ in the case of the reentry velocity impact on concrete. However, the only PICS failure occurred in the low velocity double sphere impact on concrete, in which the PICS temperature was approximately $500^{\circ} \mathrm{C}$.

The operation of each of these five tests, along with the test results and posttest analyses, is described in detail in the following report. Several important conclusions are also drawn fron these results and analyses.
\end{abstract}

\section{0 INTRODUCTION}

In preparation for the Air Force LES $8 / 9$

space mission, a series of tests were performed to evaluate the nuclear safety capability of the MultiHundred Watt (MHW) Radioisotope Thermoelectric Generator (RTG) to be used in this mission. One such safety test is Test No. S-6, Launch Pad Abort Sequential Test. 'The objective of this test was to subject the RTG and its components to the sequential environments characteristic of a catastrophic launch pad accident. This sequence of envircnments was to have consisted of the blast overpressure and fragments, followed by the fireball, low velocity impact on the launch pad, and solid propellant fire.
The blast overpressure and fragments were subsequently eliminated from this sequence. The purpose of this test is to evaluate the capability of the MHW-RTG and its components to survive such a sequence of environments.

This report describes the procedures and presents the results of Phase III of Test $>-6$, Fuel Sphere Assembly (FSA) Impacts. In this phase of the test, five impact tests were done with five simulant Fuel Sphere Assemblies (SFSAs). Three of these impacts were at low velocity, approximately $30 \mathrm{~m} / \mathrm{s}$ (100 fps), to simulate accidents that might occur during launch, and the other two were at high or terminal velocíty, approximately $87 \mathrm{~m} / \mathrm{s}$ (285 fps), 
to simulate reentry events.

Of the low velocity impacts, the first was to simulate what might be considered to be the most destructive thing that could happen to an FSA, free from MHW-RTG Heat Source Assembly (HSA), during a launch pad abort accident. This would be a iree FSA falling some 40 to $50 \mathrm{~m}$ (130 to $160 \mathrm{ft}$ ) and impacting on the edge of one of the steel members of the launch pad structure, most likely angle iron.

The other two low velocity tests were double sphere impacts, in which two SFSAs, with the center line between the two spheres perpendicular to the concrete target pad, were impacted together. These tests were designed to simulate the type of double imparts experienced by FSAs in an HSA impact, especially those that occurred during Phase 1 of the Test S-6. The two tests differed in that two Post Impact Containment Shell (PICS) temperatures were used, the normal PICS operating temperature of $1100^{\circ} \mathrm{C}\left(52000^{\circ} \mathrm{F}\right)$ and the estimated PICS temperature during the Phase I drop tesi (1) of $500^{\circ} \mathrm{C}\left(-930^{\circ} \mathrm{F}\right)$. The purpose of these tests was to determine what effect PICS temperature might have had on the results of such double sphere impacts in Phase 1 .

The high or terminal velocity impacts were conducted to sbtain information concerning the effects of concrete and compact soil on FSAs that i m jact after reentry. Before these tests, no such tariget materials have been used in reentry impact testing in the MHW program. Each of these SFSAs was subjected to a reentry heating pulse, supplied by General Electric, and impacted with a PICS temperature of approximately $1440^{\circ} \mathrm{C}\left(2624^{\circ} \mathrm{F}\right)$. Each of these five tests and the subsequent results are described in detail in the following sections.

\subsection{TEST FACILITY}

The Isotopic Fuels Impact Tester (IFiT) was designed primarily for impacting ${ }^{238} \mathrm{PuO}_{2}$ fueled capsules at anticipated reentry lemperatures and velocities. The device consists of four major parts: a projectile assembly, a gas gun, an impact chamber, and residual energy-absorbing equipment. A schematic drawing of a typical projectile assembly is shown in Fig. 2.1. Figure 2.2 shows the breech of the gun, with a blank projectile in the loaded position. Figure 2.3 is a schematic drawing of the muzale end of the gun, showing the impact chamber and energy-absorbing equipment used in the $S-6$ Phase III tests.

The gas gun has a smooth bore, $17.78 \mathrm{~cm}$ $(7 \mathrm{in})$ in diameter and $3.66 \mathrm{~m}$ (12 ft) long. T.se gun fires vertically upwards, thus elininating the need for any fasteners to hold the test specimen to the front of the projectile. Because of the length of the device, it extends two adjacent floor levels, as indicated in Figs. 2.2 and 2. 3.

The projectile assembly, Fig. 2.1, is designed to do several functions and consists of four main parts: the outer-projectile cylinder (OPC), the inner-projectile cylinder (IPC), the capsule containing the test specimen, and the furnace. The outer-projectile cylinder is nominally the bore diameter, is usually made of aluminum, has several penetrations for the furnace leads and instrumentation, and is water cooled. It is the r aject which is directly driven by the propulsion gas and is the part of the projectile that mates with the trigger system. Furnace and instrument penetrations through the OPC must be capable of sealing vacuum and pressure at all stages in the gun operation. The OPC to bore seal is accomplished with " $O$ ' rings. The OPC is held in place in the barrel before firing by a rod that is screwed into the base of the OPC, as shown in Fig. 2.2. To trigger the projectile assembly, this rod is unscrewed, thereby releasing the assembly.

The inner-projectile cyiinder is set in a recess on the leading face of the $O P C$ and consists of tapered molybdenum and nickel cylinders with a boron-nitride insulator between them. The capsules 
containirg the test FSAs for the single sphere impacts were $0.05-\mathrm{mm}$-thick (0.002 in) tantalum,

$7.62 \mathrm{~cm}$ ( $3 \mathrm{in}$ ) in diameter and $7.62 \mathrm{~cm}$ (3 in) long. The capsules, used in the double sphere impacts were made of graphite cylinders, with inside dimensions designed to hold the two spheres in the proper orientation. An electron-beam (EB) furnace with three filaments is built around the capsule. These filaments, when heated resistively, emit electrons that are accelerated into the capsule by a high voltage $(200-2000 \mathrm{~V})$ between the capsule and filaments. The kinetic energy of these electrons is converted to thermal energy as they impact, resulting in direct and efficient heating of the capsule,

The impact chamber is directly coupled and sealed to the gun muzzle, as shown in Fig. 2.3. It consists of an outer-catc's tube (OCT) assembly an inner-catch tube ( $\mathrm{I}^{\prime} \mathrm{T}$ ) (referred to in the figure as the IPC Stopping Fixture), and a target container. These catch tubes, which consist of tapered-cylindrical fixtures, are designed to stop the OPC and IPC, allowing only the test specimen in the capsule to impact the target. These catch tubes also serve to seal off the impact chamber from the rest of the gun, when the OPC and IPC are jammed into the OCT and ICT, respectively. This, of course, prevents debris as well as the test specimen from falling back down through the gun barrel, confining any release or radioactive contamination to the impact chanber.

Must of the kinetic energy of the projectile assembly is dissipated in plastic deformation of the OPC, the IPC, and the ICT. The residual kinetic energy is absorbed by the elastic stretching of the eight tie rods connected to the top of the OCT assembly.

Situated between the OC'T and the gun muzzle is a velocity pin ring, which is a fixture holding 10 rlectrically active pins spaced at known inc rements along the centerline of the gun. As each pin is contacted by the OPC, a pulse is recorded on an oscilloscope. By adding pulses from a time-mark generator to the oscilloscope input, the time between pulses can be accurately determined. With knowledge of the time between pulses sot. the pin spacings, the velocity of the frojectile assembly can be calculated.

The temperature of the capsule holding the test specimen is measured by a thermocouple attached to the surface of the capsule. A digital voltmeter and printer are used to measure anc record the thermocouple voltage continuously, prior to firing.

A diffusion-pumped vacuum system is connected to the gun muzzle to reduce the absolute pressure inside the barrel and impact chamber to below $60 \mathrm{mPa}$. This is recesisary not only for the operation of the EB furnace, but also to insure a more predictable operation of the gun itself.

\subsection{TEST DESCRIPTIONS}

¿. 1. Angle Iron Impact

3.1. 1. Test Operation. This test was designed to simulate an FSA, removed from the HSA, falling 40 to $50 \mathrm{~m}$ and impacting on a piece of the angle iron that is part of the structural steel of the launch pad. Such an impact would occur at about $30 \mathrm{~m} / \mathrm{s}$ (100 fps) with a PICS temperature of approximately $1100^{\circ} \mathrm{C}\left(2010^{\circ} \mathrm{F}\right)$. The case considered in this test was that involving an impact of the FSA on an edge of such a piece of angle iron. For this simulation. the iarget was constructed by cutting through the $-11-\mathrm{mm}$-thick (0.425 in) web of a standard $8 \times 4 \times 23$ I-beam along its length, and rounding the edges of the web. A cross section of the target and the orientation of the test FSA at impact are shown in Fig. 3.1.

The FSA used in this test, MHT-39, consisted of a Graphite Impact Shell (GIS), an Engelhardt-Type Il Ir PICS, and a thoria-simulant fuel spliere $(76 \%$ TD). The capsule used to hold the FSA in position on the projectile assembly was made of $0.05-\mathrm{mm}$-thick (0.002 in) tantalum and was loosely spot welded together. The capsule was heated to $1100^{\circ} \mathrm{C}$ in the $\mathrm{EL}$ furnace and then held at that 
temperature for at least $30 \mathrm{~min}$ before firing. The gun was set to accelerate the capsule and FSA to approximately $30 \mathrm{~m} / \mathrm{s}(100 \mathrm{fps})$ at impact, with the FSA oriented to impact $s$ indicated in Fig. 3. 1.

After the firing and specimen cool-down, the impact chamber was removed from the gun and the FSA recovered for posttest examinations.

3. 1.2. Results, The PICS temperature at the time of impact was approximately $1100^{\circ} \mathrm{C}$. The actual impact velocity was $32.4 \mathrm{~m} / \mathrm{s}$ (106 fps), with the orientation of the FSA and target very near that shown in Fig. 3.1.

As a result of the impact, the tantalum capsule was nearly destroyed, but remained loosely wrapped around the GIS. At first glance, it appeared as if the FSA had missed the target completely. However, closer inspection revealed that a direct hit had been achieved. The only evidence of the impact on the ixterior of the GIS can be seen at the top, as it appears in Fig. 3.2. The damage to the Cils was more apparent on the interior, as can be ifen in lig. 3.3. When the PISA was removed from this (uls, the accuracy of the impact became apparent, as indicated by the deformation shown in Figs. 3.4 and 3.5.

The PICS, though badly deformed by the impact, showed no evidence of cracks or breaches of any kind. The resulting minimum diameter or height of the PICS, measured at the center of the dent, was $34.85 \mathrm{~mm}(1.372 \mathrm{in})$. This indicates a maximum depth at the center of the dent of 5.842 $\mathrm{mm}(0.230 \mathrm{in})$. The average diameter of the PICS, measured in the plane perpendicular to the direction of impact, was $41.33 \mathrm{~mm}$ (1.627 in), indicating an average cliametral strain of $1.70 \%$. The resulting fliel simulant breaicup is shown in the three radiographs given in Pig. 3.6. Destructive posttest examinations have not been done, due to the possible use of this FSA in the solid propellant fire tests in Phase II of S-6.
3. 2. Double Sphere Impact (Launch Pad 'Temperature)

3.2.1. Lest Operation. In the event of an impact of an HSA on the launch pad during an abort, there is a rea:sonable probability that the attitude of the impact will be such that two or more of the FSA's in the HSA will be nearly in line with each other. Such an orientation would result in the lead FSA impacting on the target and then being struck from behind by one or more trailing FSAs. Experience from the Phase I S-6 drop test has shown that in such a "double" impact, the major deformation to the lead FSA is caused by the trailing FSA, and not the initial impact. This test was designed to simulate just such a "double" sphere impact, the results of which should help verify some of the conclusions drawn from the deformations that resulted from he Phase 1 drop test. (1)

To simulate this type of impact, $t w \cdot 3$ FSAs were placed in a graphit: capsule on the projectile assembly so that the centerline between the two was aligned with the centerlire of the gun barrel. The lead FSA, which was the primary test specimen (MHT-41), contained an Engelhardt Type II Ir PICS, while the traiinin FSA enıloyed a $T-111$ PICS. Both FSAs contained thoria ( $76 \%$ TD) fuel simuiant. The two spheres were placed in the graphite capsule in the orientation shown in Fig. 3.7. designed to approximate the alipnment of the GIS caps during an HSA impact, such as that encouistered in the Phase I drop test. The graphite capsule used in this test, in place on the projectile assembly and surrounded by the filaments of the EB furnace, is shown in Fig. 3.8. Also shown are the thermocouple leads, running from the upper part of the capsule to the insulytor on the projectile assembly.

The test was conducted by preheating the capsule and FSAs to approximately $1100^{\circ} \mathrm{C}$ and holding them at thist temperature for at least 30 min before firing. The gas gun was set to impact 
the FSAs and graphite capsule at about $30 \mathrm{~m} / \mathrm{s}$ (100 fps). After firing, the impact chamber was removed and the two FSAs were recovered for posttest examinations.

The target for this test was a cylinder of aged concrete approximately $35 \mathrm{~cm}$ (14 in) in diameter and $35 \mathrm{~cm}$ long, designed to fit in the target container shown in Fig. 2.3. A flat surface of the concrete cylinder was exposed to the impacting FSAs through an opening in the base of the target container, approximately $20 \mathrm{~cm}(8 \mathrm{in})$ in diameter. 3.2.2. Results, The PICS temperature immediately prior to impact was $1106^{\circ} \mathrm{C}$. The actual impact velocity was $30.31 \mathrm{~m} / \mathrm{s}(99.4 \mathrm{fps})$, with the orientation of the FSAs very nearly that shown in Fig. 3.7.

The damage to the two GIS's appeared to be very ligh:, with most of the deformation occurring in the area of the caps, where the two FSAs impacted each other. The damage at the point where the GIS of the lead FSA impacted the target, shown in Fig. 3.9, is obviously very light. However, the damage to the cap and thread area of the body of the lead GIS, shown in Fig. 3.10, is more apparent. Even so, the GIS could be disassembled by unscrewing the damaged cap.

The defornation of the Ir PICS can be seen in Figs. 3.11-13. Comparing Figs. 3.12 and 3.13, it becomes apparent that the major deformation to this PICS was due to the impact by the second FSA and not the initial impact on the target. This, of course, was also the case in the Phase I drop test. Though badly deformed, the PICS showed no evidence of cracks or breaches of any kind. The resulting "height" of this Ir PICS was found to be $33.78 \mathrm{~mm}$ (1.330 in), with an average diameter of $41.22 \mathrm{~mm}$ (1.623 in). This indicates an average diametral strain of $1.4 \%$. The resulting fuel simulant breakup is shown in the three radiographs given in Fig. 3.14. Destructive posttest examinations have not been done, due to the possible use of this FSA in the solid propellant fire tests in Phase $\amalg$ of the S- 6 test.

3. 3. Double Sphere Impact (Low Temperature)

3.3. 1. Test Operation, During the S-6

Phase I drop test, several of the multiple sphere impacts, described in Sec, 3.2 of this report, occurred. The resulting damage to the FSAs and deformation to the Ir PICS were very similar to that of the double sphere impact reported in Sec. 3.2. The major difference was the cracking in the Ir PICS that occurred in the Phase I drop test. in view of the fact that, with similar deformation, no cracks in the Ir PICS occurred in the double sphere impact and no cracks occurred in the case of the angle iron impact, where the deformation was more severe, it was felt to be desirable to test a second double sphere sample at a low temperature.

The PICS temperature at the time of impact for the Phase I drop test was on the order of $500^{\circ} \mathrm{C}$, (1) considerably below the normal on-pad PICS operation temperature of approximately $1100^{\circ} \mathrm{C}$. This test was conducted in exactly the same way as the one described in Sec. 3.2 of this report with one exception, the preheat was to $500^{\circ} \mathrm{C}$ instead of $1100^{\circ} \mathrm{C}$, and the furnace was held at that temperature for $2 \mathrm{~h}$ before firing instead of $30 \mathrm{~min}$.

The primary test FSA used for this test, MHT - 42, was as nearly identical as possible to MHT-41, used in the previous double sphere impact. It contained an Engelhardt Type II Ir PICS and a thoria (76\% TD) simulant fuel sphere. The second or trailing FSA contained a T-111 PICS as in the previous case.

3.3.2. Hesults, The PICS temperature at the time of impact was determined to be approximately $j 00^{\circ} \mathrm{C}$. The actual impact velocity was $30.23 \mathrm{~m} / \mathrm{s}(99.17 \mathrm{fps})$, with the orientation of the FSAs as shown in Fig. 3.7.

The damage to the GIS of the lead FSA was very similar to that of the previous double sphere impact, as can be seen by comparing Figs. 3.15 and 3.16 with Figs. 3.9 and 3.10, respectively. 
The gross deformation to the Ir PICS was also very similar. If Figs. 3.17-19 are compared to Figs. 3.11-13, it is evident that the only major difference was that the PICS in this low temperature impact cracked. Four enlarged views of these cracks are given in Fig. 3.20. They are quite similar to those that occurred in the S-6 Phase I drop test. This confirms that the low PICS temperature was probably the main cause of the PICS failures in the Phase I drop test, and not the severity of the deformation.

The resulting "height" of the Ir PICS in this test was found to be approximately $33.3 \mathrm{~mm}$ $(1.31 \mathrm{in})$, with an average diameter of $4.1 .71 \mathrm{~mm}$ (1.64 in). Due to a failure of the weld joint, the later measurement does not represent a true diametrical strain. The resulting fuel simulant breakup is shown in the three radiographs given in Fig. 3.21. As was the case of the PICS deformation, this fuel simulari breakipip looks very similar to that of the previous double sphere impact reported in Sec. 3.2.

\section{4 Reentry Impact on Concrete}

3.4.1. Test Operation. In the past, there have been many FSA impact tests at reentry velocities and temperatures. To date, all of these tests have been conducted with granite as a target. The main reason for the use of granite has been the desire to provide one of the hardest possible target materials that the FSA might impact after a reentry. Granite is also available with reproducible properties and can be made into small targets, which are useful in meeting the need to contain the FSA and target in a small volume after impact. Confinement of the FSA and target is necessary to insure the control of radioactive contamination that may result from the breach of a ${ }^{238} \mathrm{PuO}_{2}$ fueled capsule. Since there is a reasonable porticn of the earth's surface covered with concrete, it was felt that an impact or a flat concrete surface at reentry velocity and temperature would provide additional useful data. Therefore, this test was designed to simulate the impact of an FSA on concrete after a reentry from earth orbit.

The FSA used in this "ast (MHT-45) was the only FSA completely undamiged in the S-6 Phase I drop test, due primarily to its position in the HSA. It contained an Engelhardt Type III Ir PICS and a thoria (76\% TD) simulant fuel sphere. The GIS was also completly undamaged in the Phase I drop test and was used again in this impact test.

The target was the same size concrete cylinder used in the double sphere impacts described in Secs. 3.2 and 3.3. Since thoria was used as a fuel simulant, the need for containment was somewhat relaxed and the large impact chamber shown in Fig. 2.3 could be used for this test.

The test FSA was placed in a tantalum capsule, approximately $0.05 \mathrm{~mm}(0.002 \mathrm{in})$ thick, and the capsule placed in the EB furnace on the face of the projectile assembly. They were then subjected to a reentry pulse preheat cycle. This involves suijecting the FSA to the temperatures it would "see" as it reenters the earth's atmosphere. This temperature profile: was provided by G.E. . with the corresponding (apsule temperatures determined from this profile by APL. (2)

The gas gun was siet so that the FSA woulc impact at a velocity of approximately $87 \mathrm{~m} / \mathrm{s}$ ( $285 \mathrm{fps}$ ). The time o" firing was set so that the PICS temperature at impact would be that experienced during a normal impact after reentry. After the test, the impact chamber was removed, checked for radioactive contamination, and the remains of the test FSA recovered for pasttest examinations.

3.4.2. Results, The PICS temperature at the time of impact was determined to be approximately $1440^{\circ} \mathrm{C}$. The impact velocity was detemined to be $86.9 \mathrm{~m} / \mathrm{s}$ ( $=285 \mathrm{fps}$ ), with the orientation of the FSA such that it impacted directly opposite the cap of the GIS.

As a result of the impact, the tantalum capsule and the GIS were completely destroyed, and the PISA released. The remains of the GIS are shown in Fig. 3.22. That portion of the GIS 
that is crushed between the target and the PISA during impact, known as the "biscuit", can brist seen in the center foreground of this photograph, with the remains of the cap of the GiS to the left of it.

The deformation suffered by the PICS can be seen in Figs. 3.23 and 3.24. Though the PICS was badly deformed, there were no signs of cracks or breaches and no thoria contamination could be detected on the surface of the PICS. The resulting "height" of the PISA was $30.25 \mathrm{~mm}$ (1.191 in), with an average diameter of $43.43 \mathrm{~mm}$ (1.710 in). This represents an average diametral strain of $6.77 \%$, very sinular to that observed in impacts of this type on granite. The extent of the fuel simulant breakup can be seen in the three radiographs given in Fig. 3.25.

\section{5. Reentry Impact on Soil}

3. 5. 1. Test Operation. This test was designed to simulate an impact of an FSSA on compact soil at reentry velocity and temperature. The test was done to provide information about rarth impacts in addition to the granite impacts done earlier and the concrete impact described in the previous section.

The target was constructed by first molding wet soil into an adobe brick that vas about. $250 \mathrm{~mm}$ (10 in) in diameter and $25 \mathrm{~mm}$ ( 1 in) thick. The brick was dried at about $40^{\circ} \mathrm{C}$ fo. approximately $24 \mathrm{~h}$ and then placed across the hale in the target container. The remaining volurne of the target container was then packed with dry soil. Finally, a thin polyethylens: sheet was stretched across the hole in the target container to prevent dirt from falling into the gun barrel.

The FSA used in this test, MHT-58, contained anORNL Type (WC) Ir PICS and a thoria (76\% TD) simulant fuel sphere. It was contained on top of the projectile assembly in a $0,05-\mathrm{mm}^{-}$ thick (0.002 in) tantalum capsule, and oriented such that the cap of the GIS would be directly opposite the point of initial impact on the tarset.
The FSA was subjected to a reentry heating cycle as described in the preceding section, with the impact velocity set to be approximately 87 $\mathrm{m} / \mathrm{s}(\sim 285 \mathrm{fps})$. After the test, the impact chamber was removed and the FSA recovered for posttest examinations.

3. 5.2. Results. The PICS temperature at the tirne of impact was approximateiy $1440^{\circ} \mathrm{C}$, as a result of the reentry heating pulse. The impact velocity was $86.3 \mathrm{~m} / \mathrm{s}(-283 \mathrm{fps})$, with the orientation of the FSA such that it impacted opposite the cap of the GIS as planned.

The impact badly deformed the tantalum capsule and wrapped it around the FSA, as can be seen in Fig. 3.26. It was apparent wien the tantalum capsule was removed that the GIS, shown in Fig. 3.27, had suffered very little damage.

Deformation of the PICS was so slight that it could only be detected after very close inspection. The point of the main deformation is shown in Fig. 3. 22. The resulting "height" of the PIC was found to be $10.03 \mathrm{~mm}(1.576 \mathrm{in})$, with an average diameter of $40.69 \mathrm{~mm}(1.602 \mathrm{in})$. This represents almost no diametral strain.

The fuel simulant had cracks in one plane, as indicated in the three radiographs given in Fig. 3.29. but showed no significant breakup.

\subsection{DISCUSSION}

The results of the five impact tests described in the previous sections of this report are summarized in Table 4.1. In the following discussion, these tests will be referred to by the test number given in that table. The three types of iridium PICS are referred to in the table as Engelhardt Type $\amalg$ (EI-II), Engelhardt Type III (EI-III), and URNL (15C).

The restilts of Test $\# 1$, indicate that there is little chance of failure of a PICS due to wispact with structural steel of the launch pad at fallback velowities and temperatures. Of course, one could imagine higher velocities and targets with 
sharper edges, both of which would be more destructive. However, as the height from which an FSA falls increases or the width of the target decreases, the probability of a direct hit decreases. It is felt that due to the glancing nature of an indirect impact by a spherical object, anything but a direct hit, in which the velocity of the center of the sphere is directed at the middle of the target, would reduce the damage to the PICS considerably.

In discussing the significance of the results of Test \#2, first consider the relative severity of the test. The attitude of the two FSAs in the double sphere impact, inasmuch as one is directly behind the other, is the most destructive attitude for this type impact. The probability of such an exact line up cocurring in an HSA impact is small. Therefore, in this respect, this test was severe compared to an HSA launch pad impact. On the other hand, it is possible to imagine the HSA impacting at a greater velocity, resulting in a more destructive impact. However, due to an increase in dispersion with attitude in a launch pad abort situation, the probability of an on-pad impact decreases rapidly as the height from which the HSA falls increases.

With this in mind, there are two main points to be made about the results of Test \#2. First, it seems very probable that the PICS in the MHW HSA would survive a launch pad impact in a launch abort situation. Second, even if a breach did occur in one of the PICS, the fact that it would probably remain completely contained by the GIS during such a low velocity impact dictates that no prompt release of significant amounts of fuel fines should occur. Of course, encounters with the solid propellant fire environment by such a damaged FSA could result in a fuel release, but the results of the S-6, Phase $I$ test indicate that the more severely damaged. FSAs tend to be contained within the remains of the damaged HSA. This, of course, would provide such damaged or breached FSAs additional protection from the effects of the fire environment.
Test \#3 was done primarily to shed some light on the possible causes of the failures of the PICS that resulted from the S-6 Phase I drop test. Comparing the operations of Test \#2 and \#3, the only significant difference in the test conditions of these two tests was the PICS temperature at the time of impact. With these test conditions, and the fact that the resulting PICS deformation was nearly identical in the two tests, one has to conclude that the PICS failures in Test \#3 and, therefore, in the S-6 Phase I drop test, were most likely due to the brittle behavior of the iridium at the low PICS temperature of $500^{\circ} \mathrm{C}$. This is not to say that if the PICS temperature in the Phase I test had been at $1100^{\circ} \mathrm{C}$ there would have been no failures at all, but there is a high probability that this would have been the case.

The only significant result of Test \#4, other than the fact that the PICS was not breached, was that the PICS deformation was very similar to that of impact tests on granite targets with similar test conditions. In view of the fact that the concrete was nearly undamaged, it would appear that the concrete surface, as is the case with granite, did not yield enough to absorb any appreciable amount of energy during the irnpact.

The results of Test \#5 indicate that just the opposite occurred with the compact soil target. That is, the target yielded to the impacting FSA in such a manner that a very large percentage of the kinetic energy of the FSA was absorbed in the breakup and displacement of the soil. Since the soil fell out of the target container during the impact, there was no way of determining the depth to which the FSA penetrated. However, there was no evidence to suggest that the FSA contacted the back of the container. In a previous test at a different facility, ${ }^{(3)}$ a steel sphere $38 \mathrm{~mm} \Leftarrow 1.50$ in) in diameter was found to penetrate soil only about $50 \mathrm{~mm}(\sim 2 \mathrm{in})$ when impacted at $86 \mathrm{~m} / \mathrm{s}$ (282 fps). 


\subsection{CONCLUSIONS}

Based on the results of these five tests and the subsequent pottest analyses, the following conclusions can be reached:

1. It is very unlikely that a PICS failure will result from a launch pad impact of an FSA or ISSA at fall-back velocities and temperatures.

2. During a near-launch pad abort and subsequent FSA or HEA low-velocity impact, the PISAs would be expected to be contained within their damaged GIS's.

3. The most probable cause of the PICS failures observed in the S-6 Phase I drop test was the low temperature. If the temperature had been $1100^{\circ} \mathrm{C}$ instead of $500^{\circ} \mathrm{C}$, there probably would have been no failures.

4. The PICS response, at reentry velocities and temperatures, during FSA impacts on concrete is very similar to that observed when the target is granite.

5. Little or no damage to the FSA is expected to result from impact on compact soil at reentry velocities and temperatures.

\section{ACKNOWLEDGEMENTS}

The authors wish to thank the personnel at the LASL gas gun facility for their help in the operation of these tests. The helpful comments and suggestions offered by R. N. R. Mulford and

S. E. Bronisz were also appreciated.

\section{REFERENCES}

1. E. C. Snow, "Safety Test No. S-6 Launch Pad Abort Sequential Test Phase I: Low-Velocity HSA Impact," LASL report LA-5705-MS (A.ugust 19747.

2. Applied Physics Laboratory, Johns Hopkins University, correspondence ANSP-L-087.

3. J. W. Hopson, private communication. 


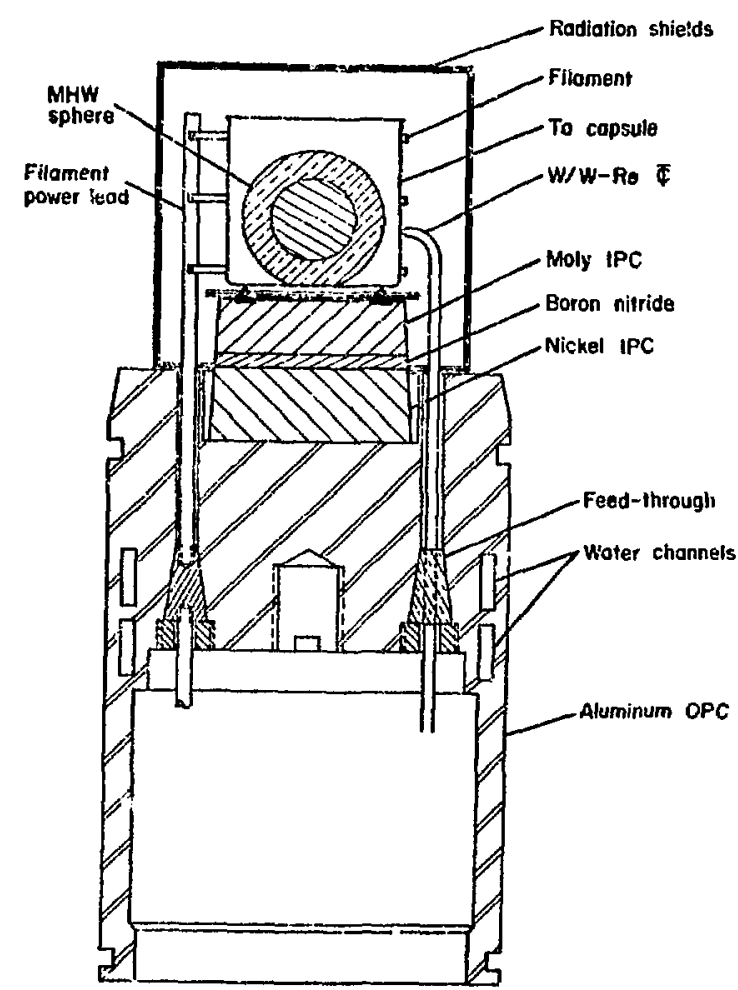

Fig. 2.1. The projectile assembly for the Isotopic Fuels Impact Tester.

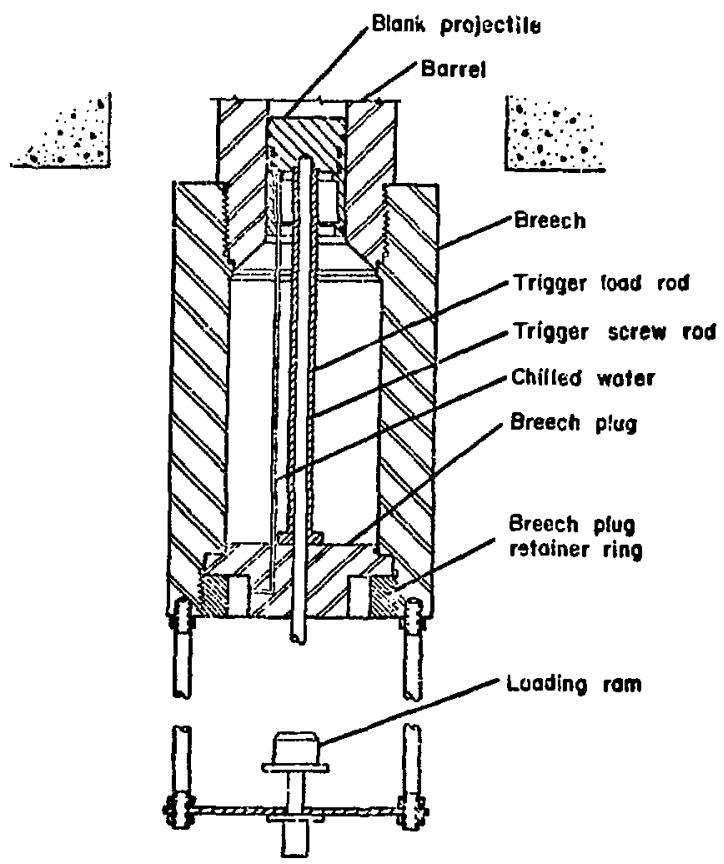

Fig. 2.2. The breach of the gas gun for the Isotopic Fuels Impact Tester.

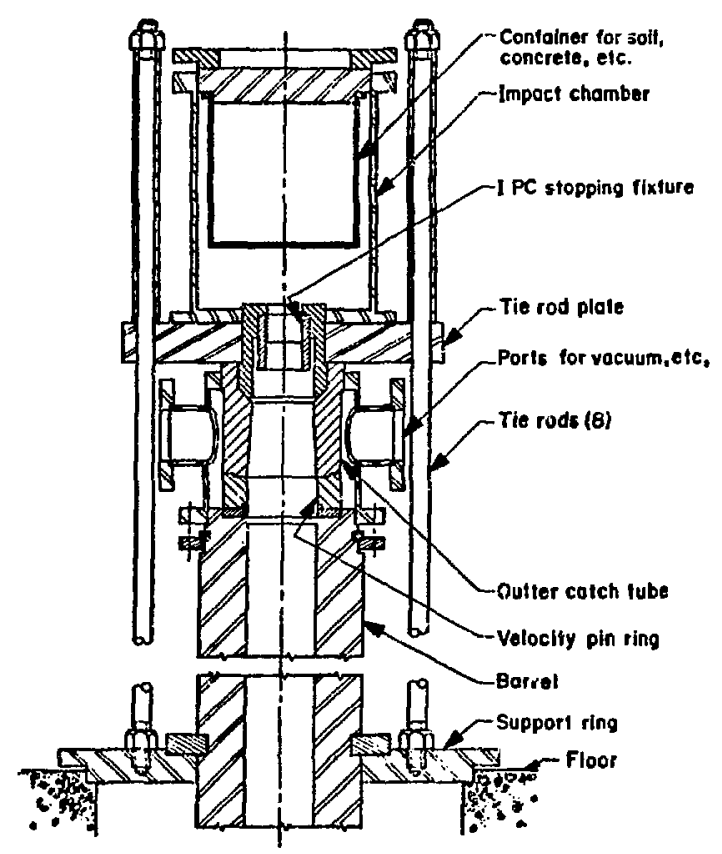

Fig. 2.3. Impact chamber setup of the Isotopic Fuels Impact Tester for S-6, Fhase III.

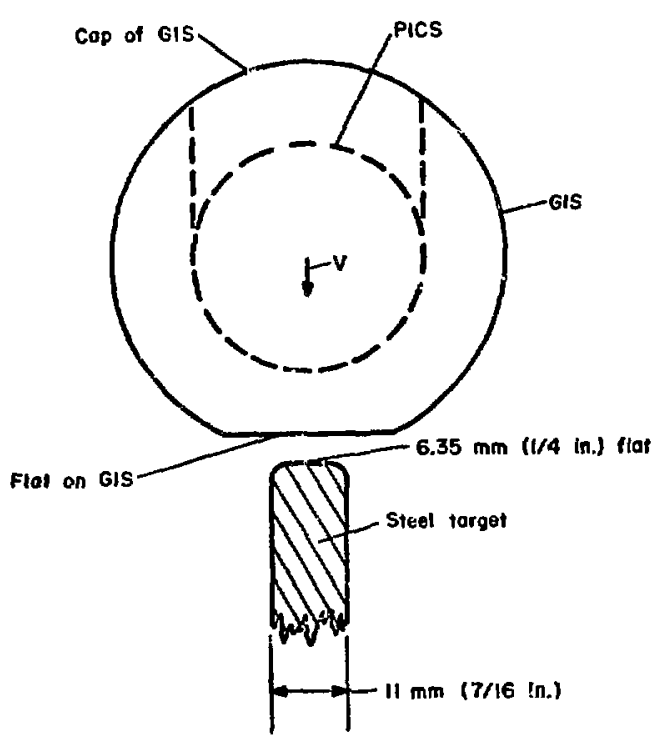

Fig. 3. 1. Orientation of FSA with respect to steel target in angle-iron impact test. 


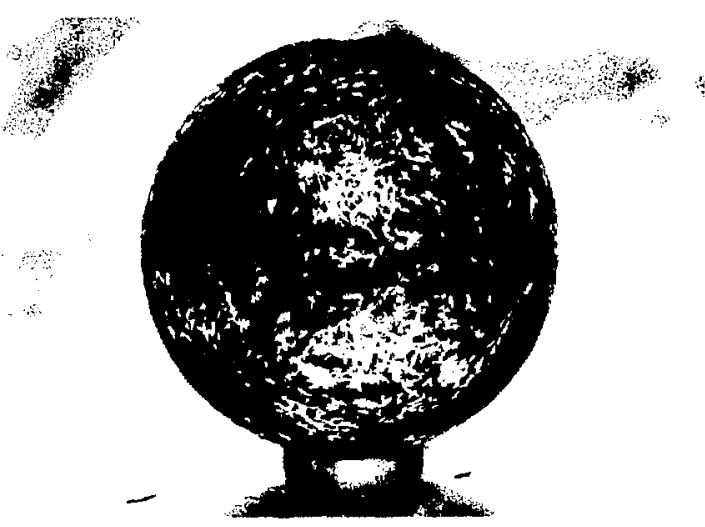

Fig. 3.2. Exterior of GIS from MHr-39 after angle-iron impact.
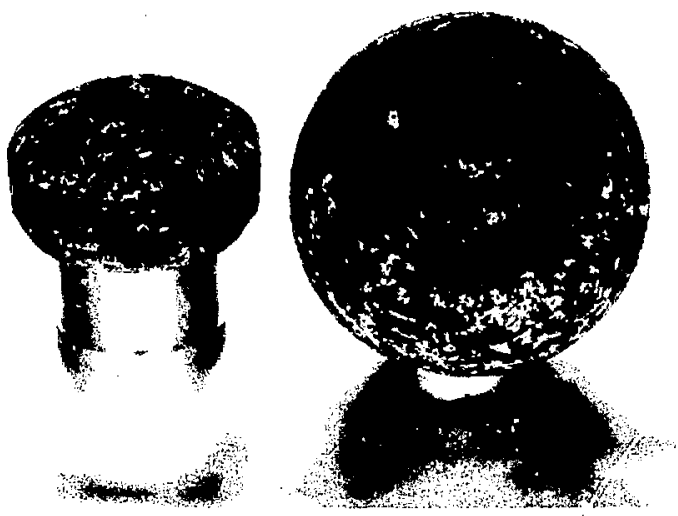

Fig. 3. 3. Interior and cap of GIS from MHT-39 after angle-iron impact.

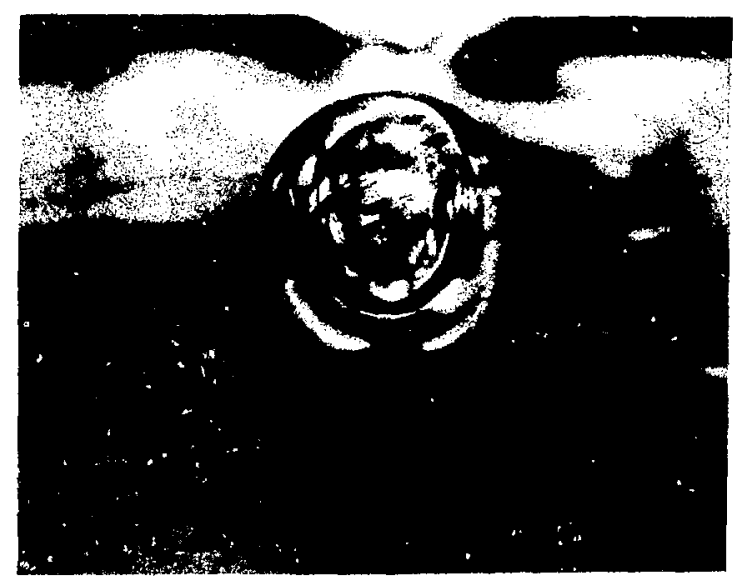

Fig. 3. 4. Point of impact on PICS from MHT-39 after angle-iron impact.

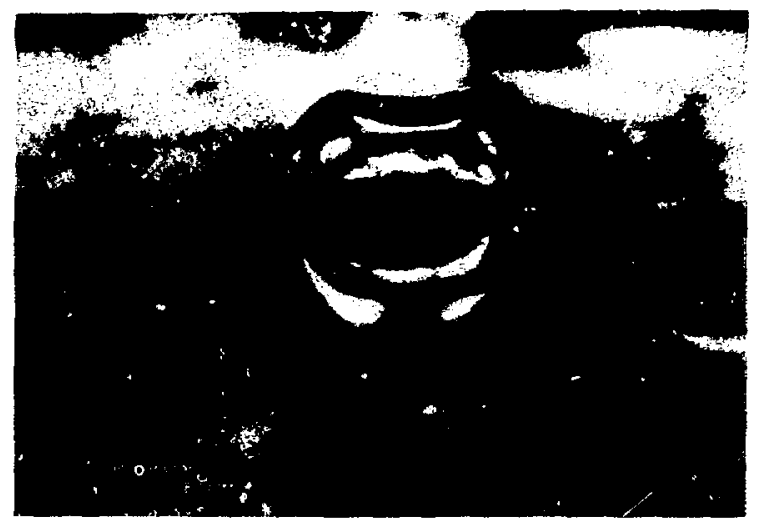

Fig. 3. 5. A view of the PICS of MHT- 39 after the angle-iron impact showing extent of deformation.
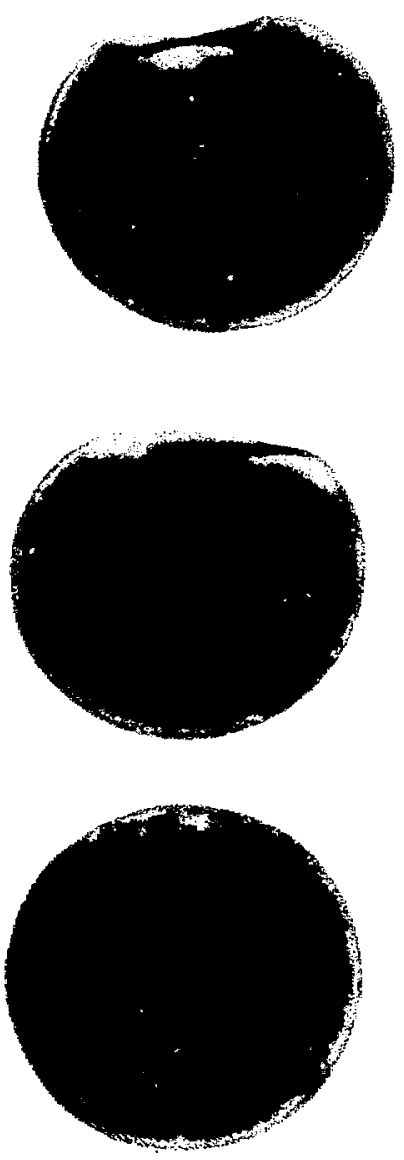

Fig. 3.6. Three radiographs taken perpendicular to each other of the PISA from MHT-39 after angle-iron impact. 


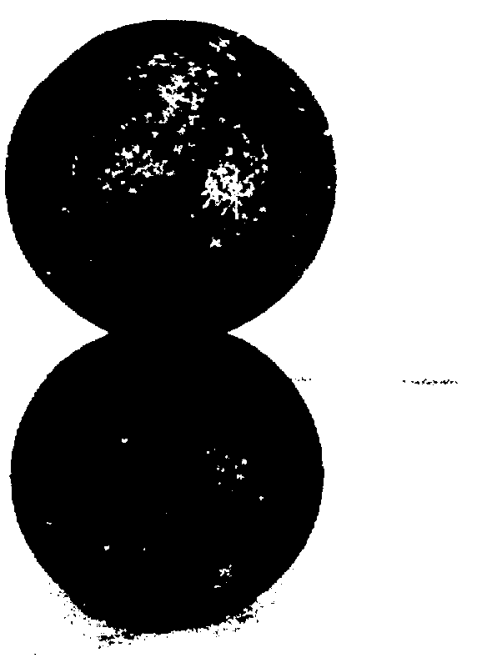

Fig. 3.7. Orientation of FSAs used in doublesphere impacts, indicating relative positions of GIS caps.

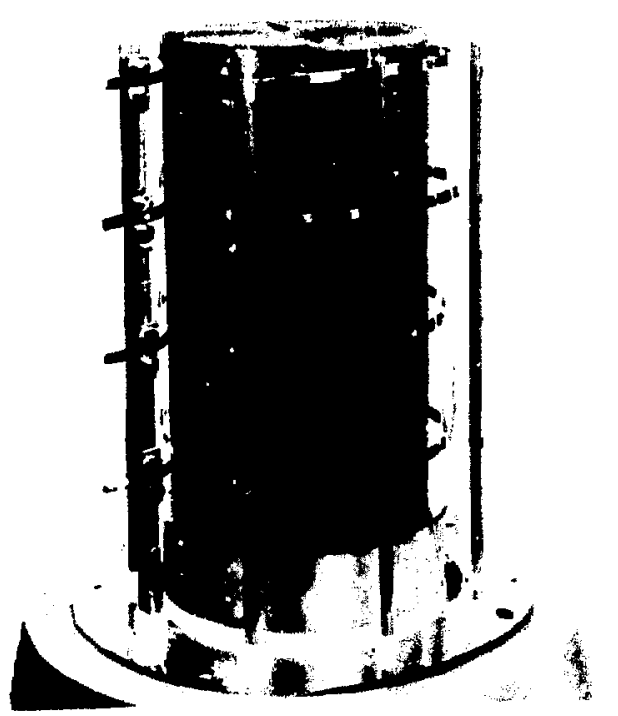

Fig. 3.8. Graphite capsule in EB furnace on projectile assembly used in double-sphere impact.

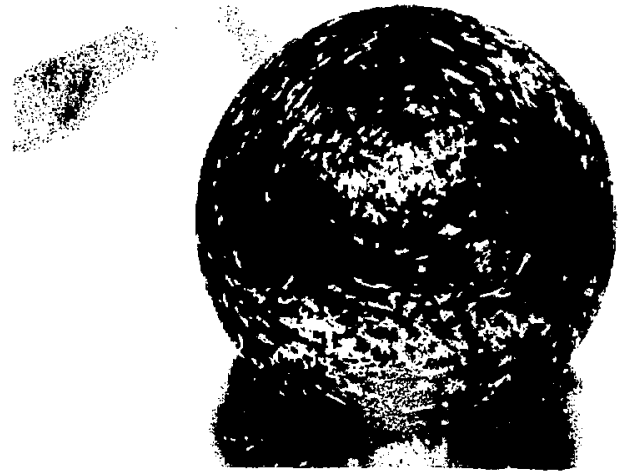

Fig. 3.9. Exterior of GIS from MHT-41 after double-sphere impact.
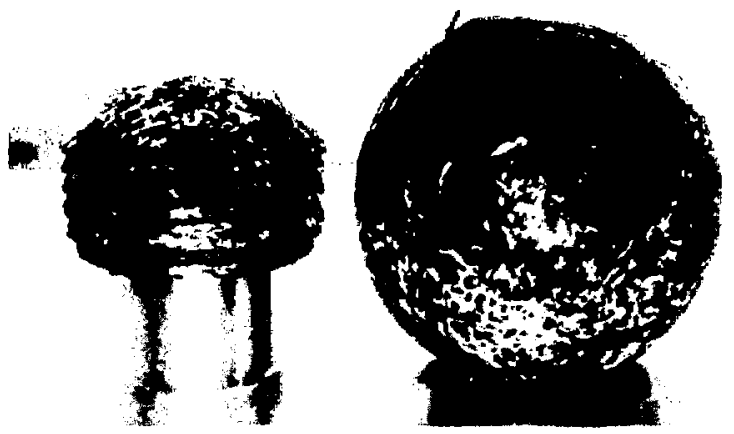

Fig. 3. 10. Interior and cap of GIS from MtT-41 after touble-sphere impact.

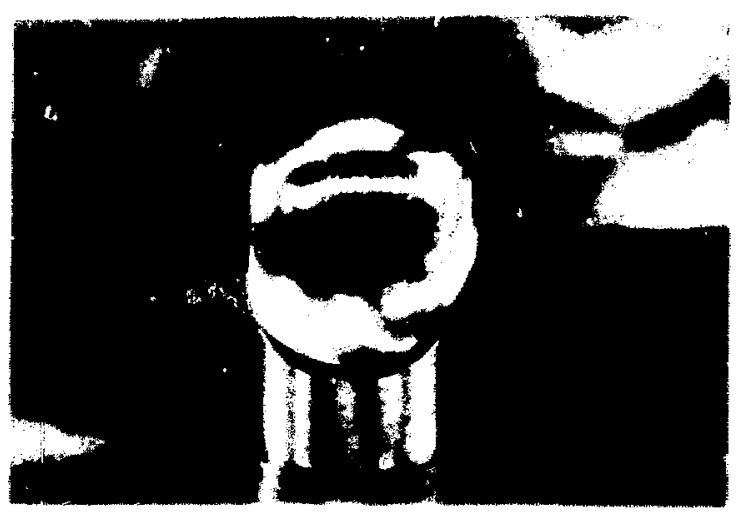

Fig. 3.11. View or MiCs from MItT-41 thowng exten of teformation in touble-yphere impact. The peimary impact is on the right and the secondsy impact on atre len at this thotocraph. 


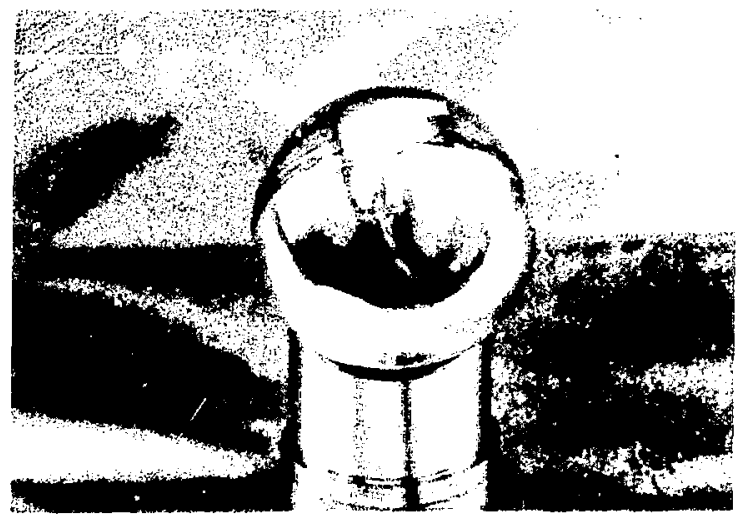

Fig. 3. 12. Point on PICS from MHT-41 where first contact was made with concrete target.

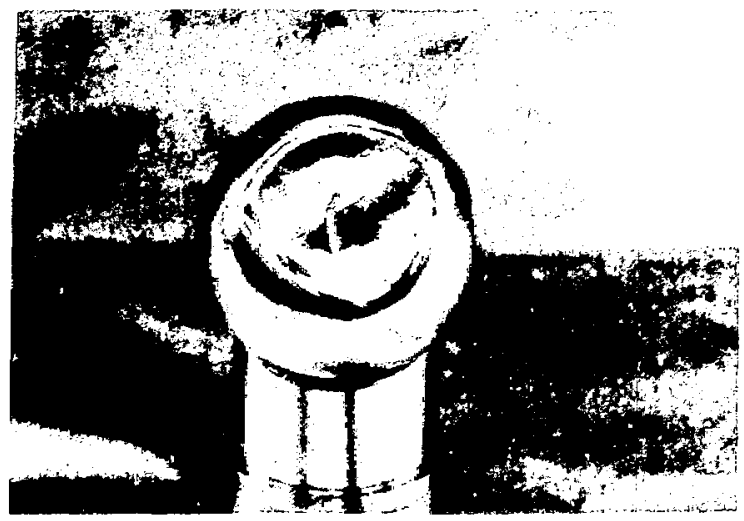

Fig. 3. 13. Point on PICS from MHT-41 where impacted by trailing T-111 FSA.
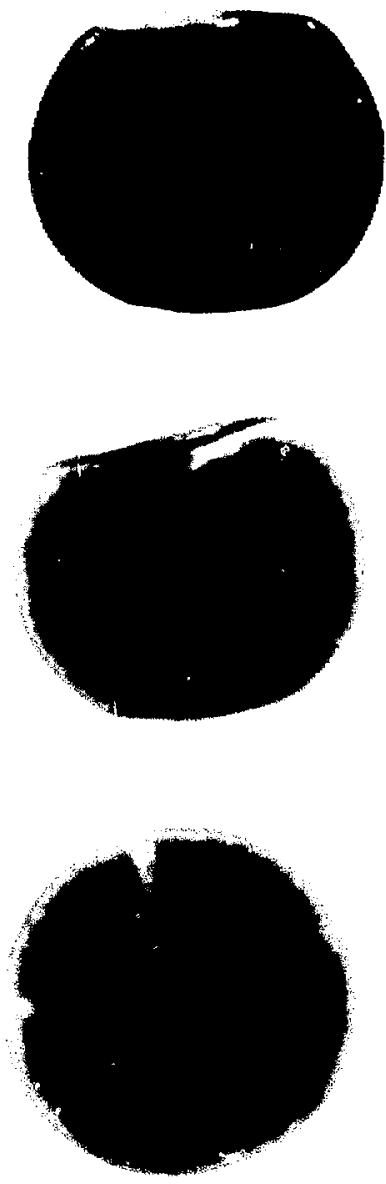

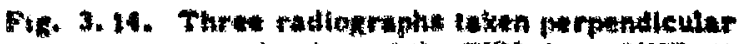

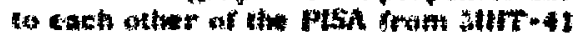

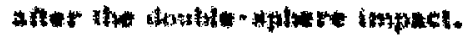

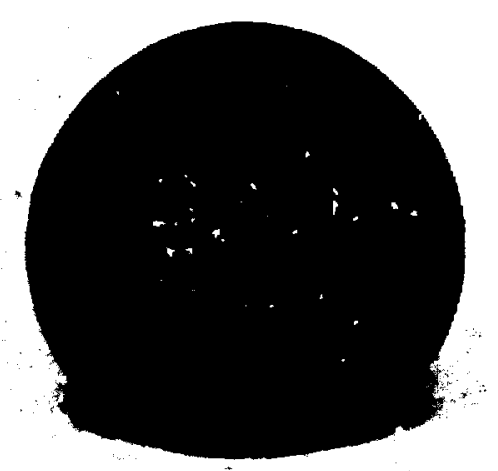

Fig. 3.15. Exterior of GIS from MHT-42 after double-sphere impact at $500^{\circ} \mathrm{C}$.

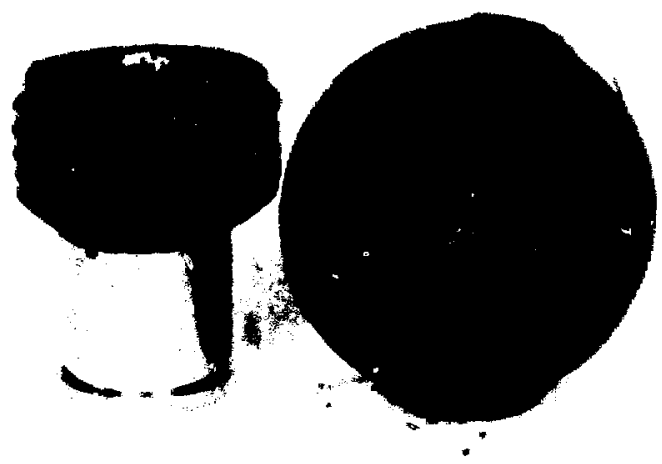

PB. 3. 16. Interior and cap of GIS from MITT-41

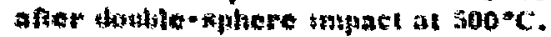




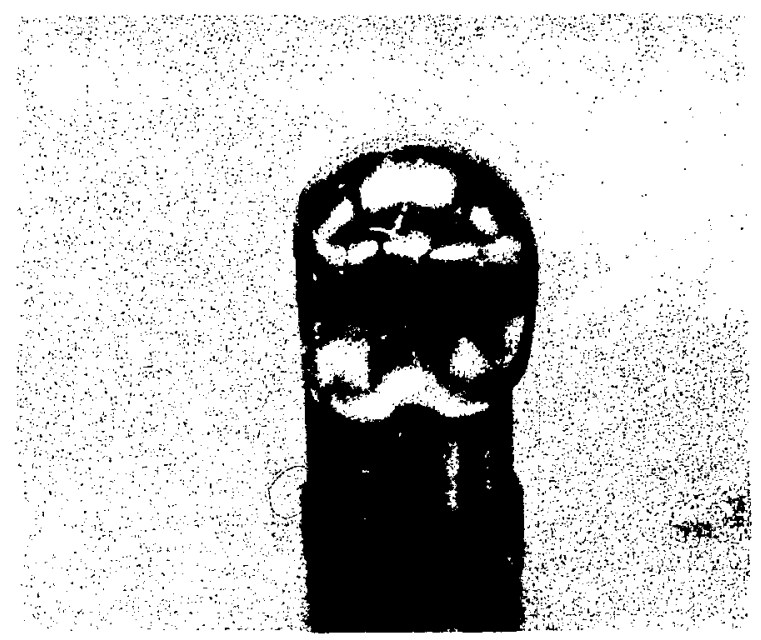

Fig. 3.17. View of PICS from MHT-42 showing extent of deformation in double-sphere impact at $500^{\circ} \mathrm{C}$. (Primary impact on right, as in Fig. 3.11.)

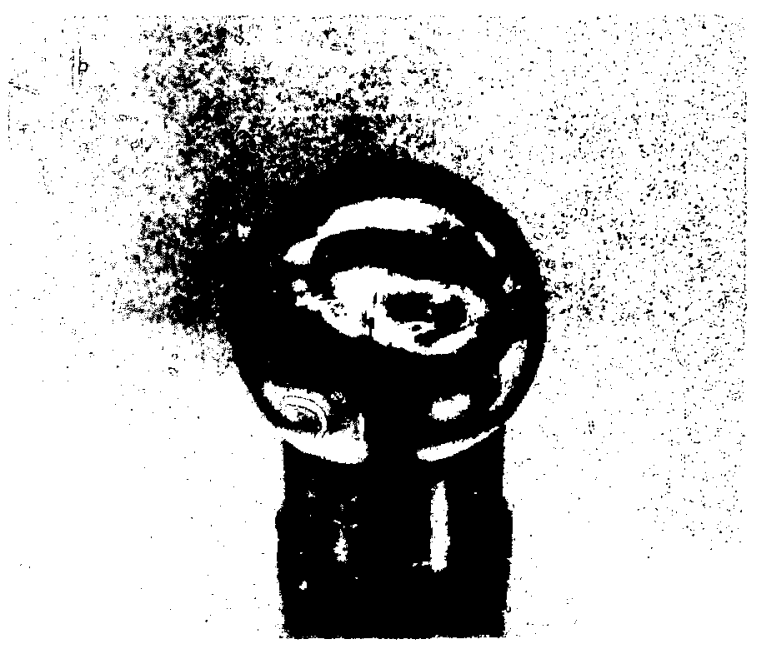

Fig. 3. 18. Point on PICS from MHT-42 where first contact was made with concrete target.

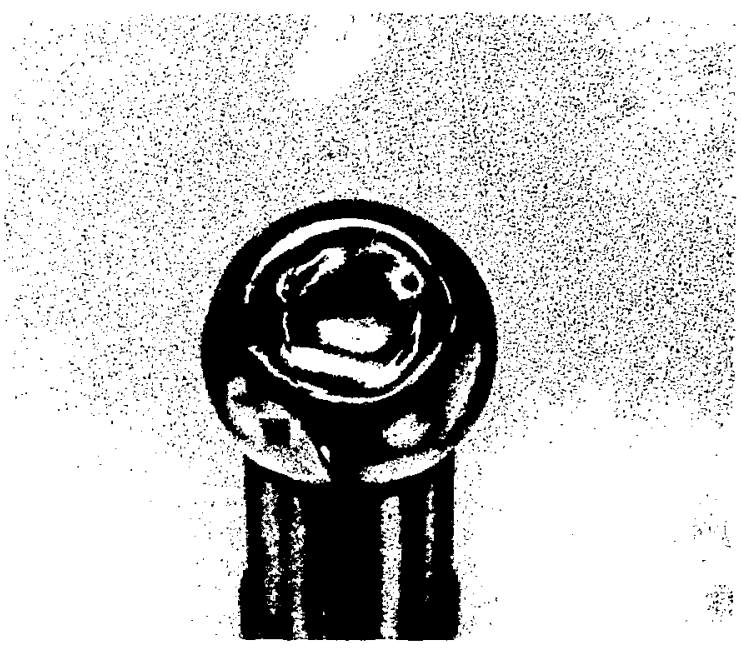

Fig. 3.19. Point on PICS from MHT-41 where impacted by trailing T-111 FSA. 

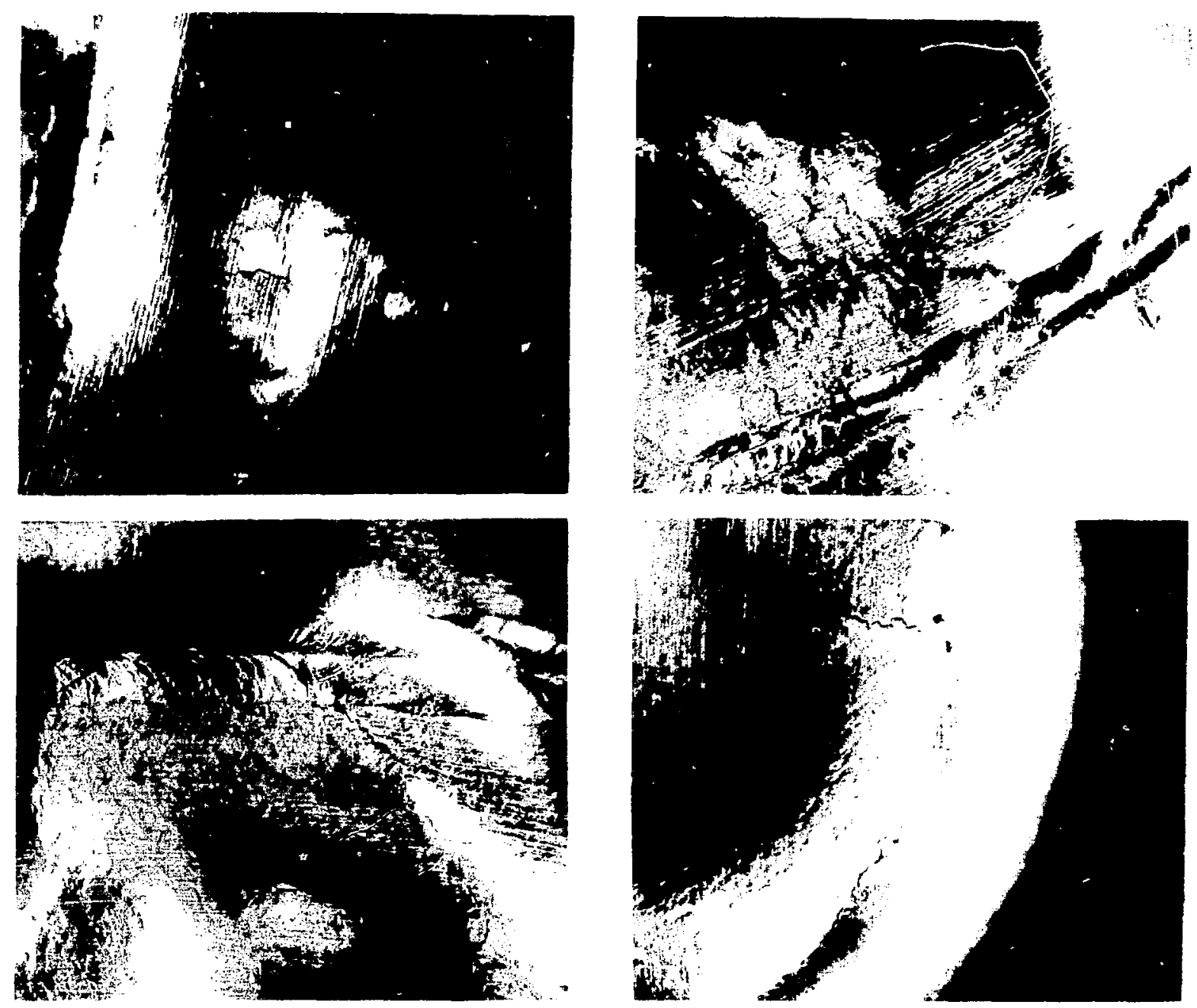

Fig. 3.20. Views of some of the cracks that occurred in the PICS from MHT-42 during the double-sphere impact at $500^{\circ} \mathrm{C} . \quad(\sim 3 \mathrm{X})$
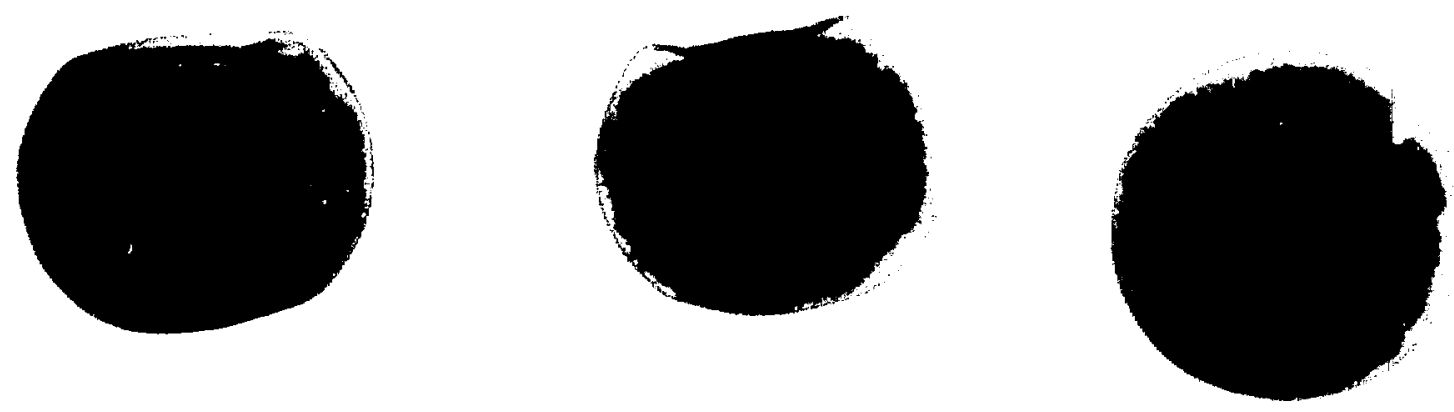

Fig. 3.21. Three radiographs taken perpendicular to each other of the PISA from MHT-42 after doublesphere impact at $500^{\circ} \mathrm{C}$. 


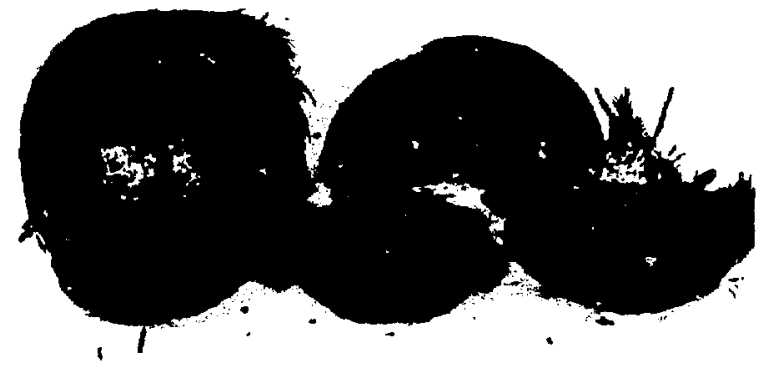

Fig. 3.22. Remains of GIS from MHT-45 after concrete impact.

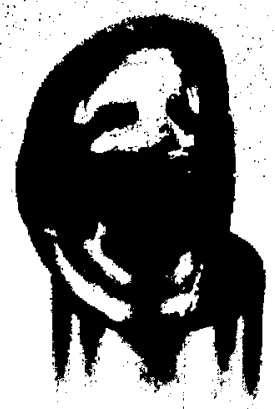

$a$

Fig. 3. 23. View of PICS from MHT-45 after concrete impact showing pxtent of deformation.

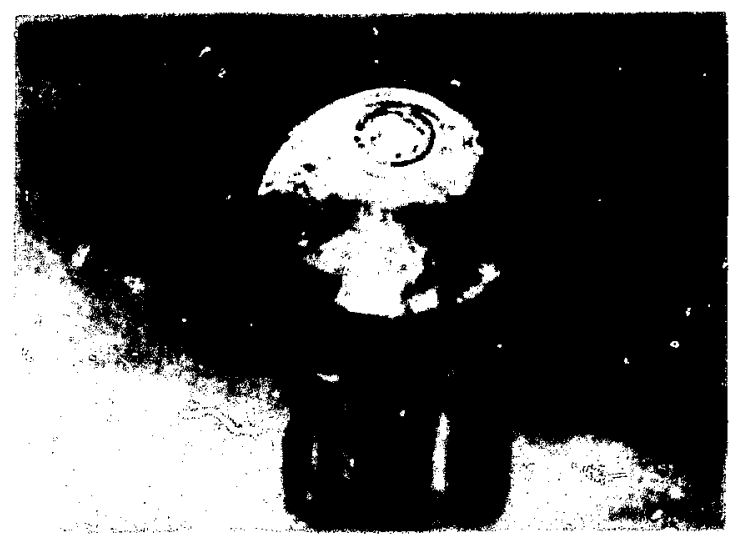

Fig. 3. 24. Point of impact on PIC's from MITT-45 afer concrote impact.
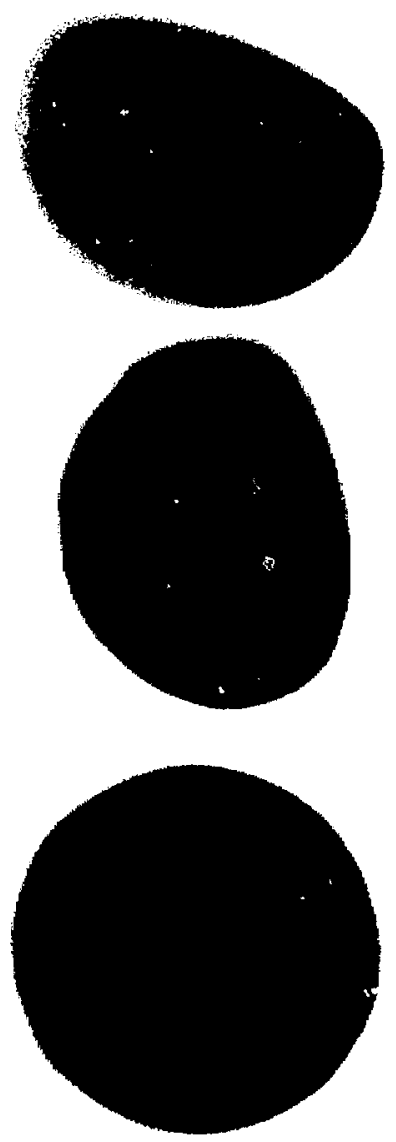

Fig. 3,25. Three radiographs taken perpendicular to each other of the PISA from MHT-45 after concrete impact.

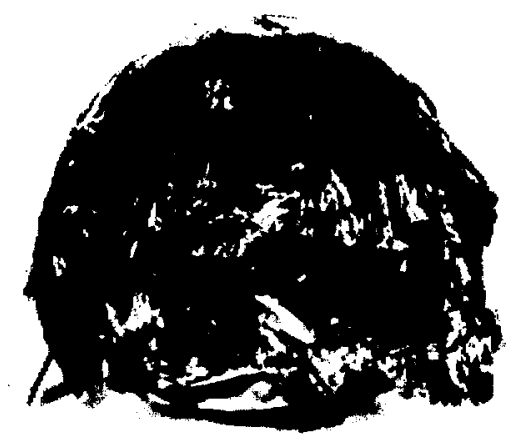

Fig. 3,26. MHT - 58 in the remains of the tantalum capsule after tive high velocity soll impact. 


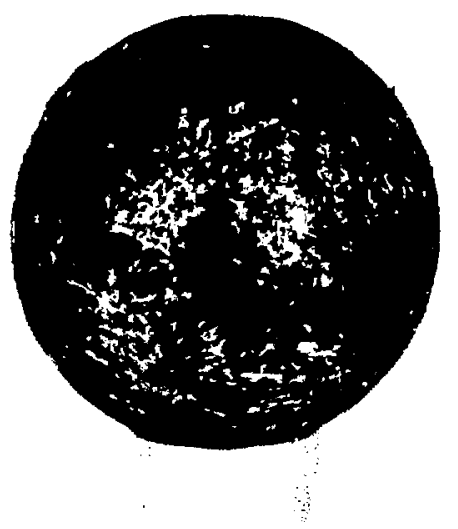

Fig. 3. 27. GIS from MHT-58 after the high-velocity soil impact.

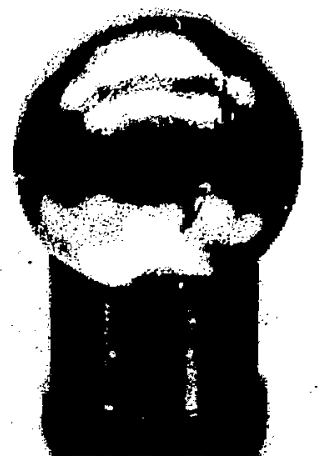

Fig. 3.28. Area of impact on PICS from MHT-58 as a result of high-velocity soil impact.
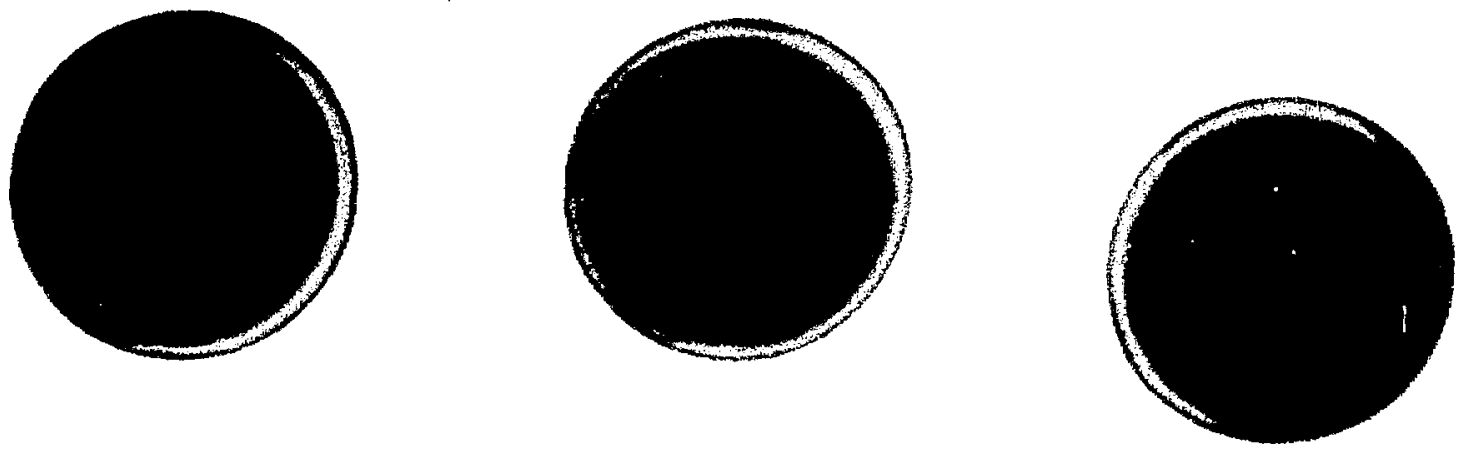

Fig. 3. 29. Three radiographs taken perpendicular to each other of the PISA from MHT-58 after highvelocity soil impact.

TABLE 4. 3.

MHW S-6, PHASE III IMPACT TEST SUMMARY

Post-1mpact Dimensions

\begin{tabular}{|c|c|c|c|c|c|c|c|c|}
\hline Test No. & $\begin{array}{c}\text { Sample No. } \\
\text { (Ir Type) }\end{array}$ & $\begin{array}{c}\text { Velocity, } \mathrm{m} / \mathrm{s} \\
\text { (fps) }\end{array}$ & $\underset{\left({ }^{\circ} \mathrm{F}\right)}{\operatorname{Temp})^{\circ}}$ & Target & $\begin{array}{c}\text { Height, } \mathrm{mm} \\
\text { (in) }\end{array}$ & $\begin{array}{c}\text { Diameter. } \mathrm{mm} \\
\text { (in) }\end{array}$ & Hoop Strain & Response \\
\hline 1 & $\begin{array}{l}\text { MHT-39 } \\
\text { (EI-II) }\end{array}$ & $\begin{array}{l}32,4 \\
(106)\end{array}$ & $\begin{array}{r}1100 \\
(2012)\end{array}$ & Sharp steel & $\begin{array}{l}34.85 \\
(1.37)\end{array}$ & $\begin{array}{l}41.33 \\
(1.63)\end{array}$ & 0.017 & $\begin{array}{l}\text { No failure after severe } \\
\text { deformation }\end{array}$ \\
\hline 2 & $\begin{array}{l}\text { MHT-412 } \\
\text { (EI-II) }\end{array}$ & $\begin{array}{l}30.3 \\
(99.4)\end{array}$ & $\begin{array}{c}1106 \\
(2022)\end{array}$ & Concrete & $\begin{array}{l}33.70 \\
(1.33)\end{array}$ & $\begin{array}{l}\$ 1.22 \\
(1.62)\end{array}$ & 0.014 & No failure \\
\hline 3 & $\begin{array}{l}\text { MHHT }-42^{2} \\
\text { (EI-II) }\end{array}$ & $\begin{array}{l}30.2 \\
(99.2)\end{array}$ & $\begin{array}{r}500 \\
(932)\end{array}$ & Concrete & $\begin{array}{l}33.27 \\
(1.31)\end{array}$ & $\begin{array}{l}41.71 \\
(1.64)\end{array}$ & $\cdots$ & $\begin{array}{l}\text { Severe weld failure and } \\
\text { cracks on rear-impact } \\
\text { area }\end{array}$ \\
\hline 4 & $\begin{array}{l}\text { MHT-45 } \\
\text { (EI-LI) }\end{array}$ & $\begin{array}{l}86.9 \\
(285)\end{array}$ & $\begin{array}{l}1440^{\mathrm{b}} \\
(1614)\end{array}$ & Concrete & $\begin{array}{l}30.25 \\
(1.19\end{array}$ & $\begin{array}{l}43.43 \\
(1.71)\end{array}$ & 0.068 & No failure \\
\hline $\mathbf{5}$ & $\begin{array}{l}\text { MHT-58 } \\
\text { (WC) }\end{array}$ & $\begin{array}{l}86.3 \\
(283)\end{array}$ & $\begin{array}{c}2440^{b} \\
(2624)\end{array}$ & Soll & $\begin{array}{l}40.03 \\
(1.58)\end{array}$ & $\begin{array}{l}40.69 \\
(1.60)\end{array}$ & $\infty$ & No taulure \\
\hline
\end{tabular}

"Double sphere impact. The sample was the lead sphere and a T-111 clad sphere wan following.

bSubjected to a reentry pulse prior .o impact. 